\title{
Interrelation of self-report, behavioural and electrophysiological measures assessing pain-related information processing
}

\author{
Oliver Dittmar, Diploma, Rüdiger Krehl, Stefan Lautenbacher PhD
}

O Dittmar, R Krehl, S Lautenbacher. Interrelation of self-report, behavioural and electrophysiological measures assessing pain-related information processing. Pain Res Manage 2011;16(1):33-40.

INTRODUCTION: A number of variables reflecting attentional and emotional mechanisms of processing pain-related information have recently attracted interest, ie, fear of pain, pain catastrophizing, hypervigilance and attentional bias to pain. These variables can be assessed by explicit measures based on conscious self-report, or by implicit measures assessing mainly preconscious stages of information processing such as behavioural or electrophysiological tests. Convergent validity within implicit measures was assumed to be high, as was the discriminant validity

METHOD: In the present study, two implicit measures (the dot-probe task for pain words and a word-processing task for pain words allowing event-related brain potential recordings) and three self-report measures (Pain Catastrophizing Scale, Pain Anxiety Symptoms Scale, and Pain Hypervigilance and Awareness Questionnaire) were administered to 27 healthy participants.

RESULTS: No significant associations were found between the implicit measures, or between the event-related brain potentials of pain words and the explicit measures. A single significant positive correlation was found between the dot-probe pain bias and the Pain Anxiety Symptoms Scale. CONCLUSION: All variables appeared to be only weakly associated. The attempt to organize the field of variables targeting attentional and emotional mechanisms of processing pain-related information using concepts such as implicit and explicit measures failed as far as the present test on convergent/discriminant validity proved.

Key Words: Dot-Probe; ERP; Pain between implicit and explicit measures.

\author{
L'interrelation entre l'autodéclaration et les \\ mesures comportementales et \\ électrophysiologiques pour évaluer le \\ traitement de l'information liée à la douleur
}

INTRODUCTION : Plusieurs variables qui reflètent les mécanismes attentionnels et émotionnels de traitement de l'information liée à la douleur ont récemment suscité l'intérêt, tels que la peur de la douleur, la catastrophisation de la douleur, l'hypervigilance et le biais attentionnel lié à la douleur. Il est possible d'évaluer ces variables par des mesures explicites fondées sur une autodéclaration consciente, ou par des mesures implicites évaluant surtout les étapes préconscientes du traitement de l'information, fournies par des tests comportementaux ou électrophysiologiques. On supposait que la validité convergente était élevée selon les mesures implicites, tout autant que la validité d'une fonction discriminante entre les mesures implicites et explicites.

MÉTHODOLOGIE : Dans le cadre de la présente étude, deux mesures implicites, soit la tâche par sondage des points sur les mots liés à la douleur et une tâche de traitement du texte pour déterminer les mots liés à la douleur permettant l'enregistrement des potentiels cérébraux liés aux événements, de même que trois mesures autodéclarées (échelle de catastrophisation de la douleur, échelle de symptômes d'anxiété vis-à-vis de la douleur et questionnaire d'hypervigilance et de sensibilisation à la douleur) ont été administrées à 27 participants en bonne santé.

RÉSULTATS : Les chercheurs n'ont constaté aucune association significative entre les mesures implicites ou entre les potentiels cérébraux liés aux événements pour déterminer les mots liés à la douleur et les mesures explicites. Ils n'ont observé qu'une corrélation positive significative entre le biais de douleur par sondage des points et l'échelle des symptômes d'anxiété vis-à-vis de la douleur.

CONCLUSION : Toutes les variables semblaient peu liées entre elles. La tentative d'organiser le domaine des variables ciblant les mécanismes attentionnels et émotionnels de traitement de l'information de la douleur au moyen de concepts comme les mesures implicites et explicites a échoué dans le cadre du présent test de validité convergente et discriminante.

$\mathrm{V}$ ariables describing the pain-related processing of information with an emphasis on attentional and emotional mechanisms such as pain anxiety (1), pain catastrophizing (2-4) or hypervigilance to pain (3) have gained interest in recent years. The quest for psychological explanations for the amplification of acute pain and the development of chronic pain has been one reason for the increase in interest $(5,6)$. Processing of pain-related information can be investigated with the help of self-report measures, behavioural tests and physiological measures. In a series of studies, self-report measures have been used with success to describe pain-vulnerable individuals. There is a lack of clarity with regard to the predictive power for pain of behavioural tests such as the modified Stroop paradigm (7) and the dot-probe task (8). These tests were originally applied in the field of anxiety and were adapted to the study of pain (Stroop paradigm, see reference 9; dot-probe task, see reference 10). These tests are based on cognitive psychology concepts applied to emotional disorders, ie, anxiety disorders or depression, which propose that concern-related stimuli receive increased attentional resources and are, thus, processed with priority (11). Some studies have found evidence for specific attentional biases for pain-related stimuli in individuals who are likely prone to bias such as pain patients and highly pain-anxious subjects (Stroop paradigm, see references 9,12,13; dot-probe task, see references 10,14; using faces, see reference 15 ; using pictorial cues, see reference 16 ), whereas other studies cannot replicate such biases (Stroop paradigm, see references 17-20; dot-probe task, see references 20-23).

Physiological measures, especially event-related brain potentials (ERPs), have also been applied successfully in predominantly clinical studies for testing altered pain-related information processing (24-29). ERPs can elucidate neural activation patterns underlying information processing on a millisecond basis. The use of physiological measures is also in accordance with the three-system approach to emotion (30), 
which describes verbal, behavioural and physiological domains as constituting emotional processes.

The relationship between these ERP measures on the one hand, and variables assessed by behavioural tests as well as self-report on the other hand, has not yet been clarified because inconsistent results have been found in healthy subjects (21-23) and pain patients (17-20). Theoretically, behavioural tests can yield evidence of preconscious stages of information processing (implicit measures); self-report measures can give evidence of the consciously available results of preconscious processes but are uninformative about the preconscious processes themselves, qualifying them, by definition, as explicit measures (31). Physiological measures can likewise be considered implicit measures tapping into preconscious stages of information processing. Therefore, these two types of measures, namely implicit and explicit ones, rely on distinctly different components of information processing and it would not be surprising to find both strong and weak correlations among them when testing their convergent (within) and discriminant (between) validity.

To our knowledge, no study has been reported in which self-report, behavioural and electrophysiological measures for pain-related information processing have been applied on one sample of subjects. Therefore, the current study aims to investigate the interrelation of these three types of measures by administering them to a nonclinical sample. As a behavioural test, the dot-probe task including pain words was used. As an electrophysiological measure, a word-processing task (29) allowing ERP recordings for pain-related words was applied. For self-report measures, the Pain Catastrophizing Scale (PCS) (2), the Pain Anxiety Symptoms Scale (PASS) (1) and the Pain Hypervigilance and Awareness Questionnaire (PVAQ) (3) were used. The following two hypotheses were tested:

1. The implicit measures (behavioural and electrophysiological measures) are significantly positively correlated (convergent validity).

2. Behavioural measures and electrophysiological measures on the one hand (implicit measures) and self-report measures (explicit measures) on the other hand are not closely correlated (discriminant validity).

\section{Subjects}

Twenty-seven individuals (14 women, mean $[ \pm$ SD] age $28.7 \pm 8.59$ years, range 19 to 43 years) participated in the present study. Subjects were recruited from the undergraduate students of the University of Bamberg (Bamberg, Germany) and from the university staff; students were offered course credits for their participation. All subjects had normal or corrected to normal vision, and German was their first language. None of the subjects had a history of psychiatric or neurological disorders. All participants were free of any medication influencing central nervous system function including analgesics. All subjects provided signed informed consent.

The present study was approved by the Ethics Committee of the University of Bamberg.

\section{Procedure}

On arrival in the laboratory, subjects were informed about the course and duration of the experiment and provided signed informed consent. Subjects were seated in a comfortable chair in front of a 20-inch computer screen ( $1 \mathrm{~m}$ viewing distance) used to present the experimental tasks. Subjects were monitored through a video camera and could communicate through a two-way communication system. All instructions were given verbally by the experimenter just before each of the experimental tasks. The experimenter left the room during the tests. First, subjects were asked to perform the dot-probe task. Practice trials were run to familiarize subjects with the task. Subsequently, electrodes for recording ERPs were attached and two phases of the word-processing task were completed by the subjects. Before the task, practice trials at a slow speed (ie, longer presentation times of stimuli) and at normal speed were run for familiarization. After completing the second phases of the word-processing task, the electrodes were removed and the PCS, PASS and PVAQ were administered to the subjects.

The order of experimental tasks was based on practical and theoretical considerations. The questionnaires, which explicitly ask about pain symptoms, fear and attention to pain, were put last in the order of tests. The intended measurement of automatic information processing biases for pain by the dot-probe task and the word-processing task might have been distorted if the issue of pain was explicitly elaborated beforehand. Electrophysiological recording can cause inconveniences through its setup, which requires the subject to wear an electrode cap. Therefore, tests such as the dot-probe task, which might be sensitive to such situational influences, were run before the ERP recordings.

\section{Materials}

Dot-probe task: The dot-probe task for pain-related stimuli used in the current study was based on the dot-probe task described by Keogh et al (10). It contains three emotional word categories: pain-related (eg, stechend [German] - stinging), social threat (eg, beschämt - ashamed) and positive words (eg, glücklich - happy). During visual presentation, the emotional words are paired with neutral words; neutral-neutral word pairs serve as filler items. The words of the original version (10) were translated into German. Because not all words fulfilled the criteria of being similar in length and frequency of use, a series of words had to be replaced. In a pilot study, each word of the new list (containing more items than necessary) was tested to see whether it was representative of the designated word category. If this was not the case, the word was excluded from use in the dot-probe task.

The trials of this task started with a fixed cross in the centre of a computer screen presented for 500 ms. Following this, two words (a neutral one paired with an emotional one) were presented concurrently, one below and one above the centre, for another $500 \mathrm{~ms}$. After this, a dot appeared at the location of one of the two words and subjects were required to indicate where the dot had appeared as quickly and accurately as possible by pressing one of two response buttons (below or above). The presentation of word-pair combinations and the location of the dot-probe were balanced over all trials. After 20 practice trials, participants had to complete 128 test trials (32 trials per word-pair category). The reaction time was measured. Dot-probe detection latencies of pain words were converted to an index of attentional bias by using the following formula: ([pudl - pldl] + [pldu pudu])/2, where $\mathrm{p}$ is the pain word, $\mathrm{d}$ is the dot, 1 is the lower position on the computer screen and $\mathrm{u}$ is the upper position. The same formula applies for social threat and positive words (17).

Self-report measures: The PCS (2) was developed as a measure of catastrophizing related to pain. It consists of 13 items that can be divided into three subscales - namely, rumination, magnification and helplessness. Items are rated on a five-point scale. Only the total score was used for further analysis. The PASS (1) (German version translated and validated by Walter et al [32]) was designed to measure fear of pain across cognitive, behavioural and physiological domains. It consists of four subscales: cognitive anxiety, escape/avoidance, fearful appraisal and physiological anxiety. Again, only the total score was used for further analysis. The PVAQ (3) is a broad measure of attention to pain. This scale consists of 16 items rated on a six-point scale regarding awareness, vigilance, observation and preoccupation with pain. The PASS and PCS were translated into German using a standard 'forward-backward' procedure. Translation accuracy was considered to be sufficient only if the resulting backward English version was very similar to the original version according to an evaluation by a native English speaker. The intercorrelations of the three German questionnaires ranged between $r=0.502$ and $r=0.741$, which is in accordance with intercorrelations reported in the literature for the original English version $(23,33,34)$.

Word-processing paradigm: The word-processing task applied in the present study was based on a paradigm described by Nikendei et al (29). The test consists of a study phase in which a limited number of 
pain and neutral words are 'learned', and a second phase with a lexical problem in which the learned words from the study phase and words not presented before are the objects of a semantic decision.

The study phase familiarized subjects with some of the presented stimulus material. The rationale of this was to control for the novelty aspect of the stimulus material, which is well known to have a noticeable impact on the ERPs.

Word stimuli: The relevant word stimuli were 36 pain-related words (eg, quälend - torturing, and brennend - burning) (29). For each pain word, a neutral control word matched for frequency of use, number of syllables and number of letters was selected. These words were all adjectives.

Study phase: For the study phase, 24 pain words and the 24 corresponding neutral adjectives were selected from the total word pool. These words had to be processed in a syntactic (type of word) or an orthographic (type of letter) task. For the two task conditions, another 48 neutral nontarget words were created to be used in the study phase only. Pain/neutral words or nontarget words were presented for $200 \mathrm{~ms}$ and subjects had to respond as quickly and accurately as possible according to the cued task condition of the specific trial, indicating whether the word was the designated word type or whether the word was written in the designated letter type. The study phase lasted $10 \mathrm{~min}$.

Lexical decision test: Seventy-two words and 72 nonwords (eg, krausell) matched in number of syllables and letters were presented in a random sequence. The 72 words consisted of 36 pain-related words and the 36 corresponding neutral words (see Word stimuli); 24 words from each category were 'learned' because they had been presented during the study phase. The subjects' task was to decide as quickly and accurately as possible whether the presented word was a meaningful German word. Subjects had two response buttons in front of their right hand - one for yes and one for no.

All 144 trials lasted $2.6 \mathrm{~s}$, and had the following sequence. First, a fixation cross was presented for $300 \mathrm{~ms}$, and then a word or nonword was presented for another $300 \mathrm{~ms}$. Responses were allowed within the next $2 \mathrm{~s}$. The intertrial interval was $2.5 \mathrm{~s}$. The number of correct responses and reaction times were registered. The lexical decision test took $12 \mathrm{~min}$.

The design of both the dot-probe task and the lexical decision test classified them as a primary task paradigm, which required the subjects to attend explicitly to stimuli or stimulus features other than the painrelated ones. Such protocols allow for better consideration of unconscious and implicit information processing.

Physiological recording: ERPs were recorded from three sites $(\mathrm{Fz}, \mathrm{Cz}$ and $\mathrm{Pz}$ ) with a commercially available electrode cap (Electro-cap International Inc, USA); tin electrodes were placed according to the international 10-20 system. Tin electrodes were placed on the mastoids (A1 and A2; linked) to be used for re-referencing the data offline. For measuring the vertical electro-oculogram (EOG), tin electrodes were placed above and below the right eye; for measuring the horizontal EOG, tin electrodes were placed at the outer canti. An electroencephalogram, including the vertical and horizontal EOG, was continuously recorded with a DC Brain Amp amplifier (Brain Products GmbH, Germany) with a sampling rate of $1000 \mathrm{~Hz}$, a notch filter at $50 \mathrm{~Hz}$, and a low-pass filter at $70 \mathrm{~Hz}$. All channels were primarily recorded with a $\mathrm{Cz}$ reference. ERP sweeps of $1200 \mathrm{~ms}$ duration, starting $200 \mathrm{~ms}$ before stimulus presentation, were extracted. Offline, sweeps were re-referenced to the linked mastoids; $\mathrm{Cz}$ data were retrieved for further analysis. Sweeps were adjusted to a $200 \mathrm{~ms}$ baseline period before trial onset. The data were corrected for EOG artefacts using a regression method (35). Subsequently, elimination of trials with artefacts was performed by automatically detecting trials with amplitudes outside a range of $\pm 50 \mu \mathrm{V}$ and by single-trial visual inspection.

N100 was defined as the most negative peak in the time range between $80 \mathrm{~ms}$ and $160 \mathrm{~ms}$ from trial onset. P100 was defined as the most positive peak in the time range of $80 \mathrm{~ms}$ to $140 \mathrm{~ms}$. N200 was defined as the most negative peak in the time range between $160 \mathrm{~ms}$ and $200 \mathrm{~ms}$ from trial onset. $\mathrm{P} 300$ was defined as the most positive peak in the time range between $260 \mathrm{~ms}$ and $400 \mathrm{~ms}$ from trial onset. Amplitude values were computed for these four components. Two variables for the late positive complex (LPC) were defined: LPC-Area was defined as the area under the curve in the time range from $400 \mathrm{~ms}$ to $800 \mathrm{~ms}$, and LPC-Peaks was defined as the most positive peak in the time range between $400 \mathrm{~ms}$ and $800 \mathrm{~ms}$ from trial onset.

Data reduction and statistical analysis

Dot-probe and self-report measures: Bias indexes for the different word categories in the dot-probe task were used, and were calculated as described above. Total scores of the PCS, PASS and PVAQ were used directly for hypothesis testing. Pearson's correlation coefficients between the three dot-probe bias measures and the PCS, PASS and PVAQ were computed and corrected for type 1 error using the Bonferroni method.

ANOVA of ERPs of different word categories: In preparation for statistical hypothesis testing by regression analyses, ERP data were analyzed by multiple ANOVAs to test the internal validity of the experimental method, ie, increased activation for critical stimuli (pain-related words) compared with 'baseline' stimuli (neutral words) and novelty effects for 'learned' and 'new' words. A set of two-way ANOVAs $(2 \times 2)$ with the factors WORDTYPE (two categories: pain words and neutral words) and NOVELTY (two categories: learned words and new words) for $\mathrm{Fz}, \mathrm{Cz}$ and $\mathrm{Pz}$ and for the six ERP components (N100, P100, N200, P300, LPC-Peaks and LPC-Area) were calculated.

Covariance analysis of ERP data: The raw values of ERPs of painrelated words are considered to be composed of neural activity due to word processing in general and due to specific processing of the critical stimulus content, ie, pain-related information. Because in further analysis the focus is on activation due to processing of critical stimulus content and not on general processing activity, a method must be considered to separate these two sources. By introducing the 'baseline' activation (ERPs of neutral words) as a covariate in ANOVAs, the specific activation due to critical stimulus content is expressed in the resulting residuals. The exclusion of variance due to general word processing makes residuals a superior parameter for further analysis compared with raw ERPs.

Eighteen repeated-measures one-factorial ANCOVAs (six ERP components by three electrode sites) were calculated, and learned neutral words were used as a covariate to receive residuals for the specific activation due to learned pain-related words. This procedure was repeated with new neutral words as a covariate to extract the residuals for the specific activation due to new pain-related words. Subsequent analyses were based on residuals.

LPC: It could be assumed that the two ERP components - LPC-Area and LPC-Peaks - are two indexes of the same process, ie, they might be highly dependent. Therefore, correlations between these two variables were calculated.

The correlations between LPC-Peaks and LPC-Area as raw values were in the range of 0.475 to 0.847 . The correlation between the residuals of LPC-Peaks and LPC-Area for pain-related words (see Covariance analysis of ERP data) was lower but still high ( $r=0.268$ to $r=0.654$; median $r=0.609$ ). The reader might consider this information when reading the results for both components.

Regression analysis: Multiple regressions with the residuals of learned and new pain-related words (see Covariance analysis of ERP data) of six different ERP components as predictors and the dot-probe bias measures (pain words, social threat words and positive words) and total scores of the PCS, PASS and PVAQ as criteria were calculated and corrected by applying the Bonferroni method. The direction of the predictions, ie, ERP data as predictors and dot-probe bias measures and questionnaires as criteria, was arbitrary because no causal or temporal relationships were assumed. Therefore, for statistical convenience, multiple ERP parameters were used as predictors for the much smaller number of dot-probe bias measures and questionnaires as criteria. Following the multiple regressions, linear regressions were 
TABLE 1

Correlations of explicit measures (questionnaires) and implicit measures (dot-probe bias measures) of painrelated information processing

\begin{tabular}{|c|c|c|c|c|c|c|}
\hline & \multicolumn{6}{|c|}{ Social threat } \\
\hline & \multicolumn{2}{|c|}{ Pain words } & \multicolumn{2}{|c|}{ words } & \multicolumn{2}{|c|}{ Positive words } \\
\hline & $r$ & $\mathbf{P}$ & $r$ & $\mathbf{P}$ & $r$ & $\mathbf{P}$ \\
\hline PVAQ & 0.190 & 0.343 & 0.021 & 0.918 & 0.170 & 0.398 \\
\hline PCS & 0.330 & 0.100 & 0.180 & 0.426 & 0.031 & 0.878 \\
\hline PASS & 0.488 & 0.012 & 0.028 & 0.890 & 0.134 & 0.505 \\
\hline
\end{tabular}

Significant results $(P \leq 0.01)$ are printed in bold. PASS Pain Anxiety Symptoms Scale; PCS Pain Catastrophizing Scale; PVAQ Pain Hypervigilance and Awareness Questionnaire

calculated for new and learned pain words separately to determine the contribution of these single predictors.

\section{RESULTS}

Dot-probe and self-report measures

Pearson's correlation coefficients between the three questionnaires and the dot-probe pain biases are shown in Table 1. Because of multiple testing, results were corrected using the Bonferroni method. Of a total of nine correlations, only the PASS and the pain word bias in the dot-probe correlated significantly $(r=0.488 ; \mathrm{P}=0.012)$. Consequently, these correlations were suggestive of only low convergence of selfreport and behavioural measures of pain-related information processing.

\section{ANOVA of the ERPs}

Figure 1 displays individual ERPs averaged over each person, elicited both by pain-related and neutral words. Although the early components N100, P100 and N200 were clearly visible, high interindividual variance prevails in the ERP signals, which often occurs in ERP studies.

A number of significant main effects for the WORDTYPE factor (pain words versus neutral words) for the ERP components P100, N200, P300 and LPC-Peaks were found with effect sizes up to eta $=0.778$ at $\mathrm{Pz} / \mathrm{LPC}$-Peaks (Table 2). Also, a number of main effects for the NOVELTY factor (learned versus new words) for the ERP components N100, P100, N200, P300 and LPC-Peaks were found with effect sizes up to eta $=0.485$ at $\mathrm{Fz} / \mathrm{P} 100$.

The main effects for the factor WORDTYPE verified the experimental setup in that the pain-related words evoked higher cortical activation than neutral words. The main effects for the NOVELTY factor indicated that a novelty effect existed, with higher signal strength for new words. Therefore, it appeared sensible to keep learned and new words as two separate variables for further statistical analysis.

\section{Regression analyses for the dot-probe task and the self-report} measures

For predicting the three dot-probe bias measures (pain words, social threat words and positive words) the two predictors 'learned pain words' and 'new pain words' were used for all ERP components (residuals corrected for baseline; see Covariance analysis of ERP data). The same prediction applies for the prediction of the three total scores of the PCS, PASS and PVAQ. This resulted in 54 regressions for the dotprobe bias measures (six ERP components by three electrode locations by three dot-probe bias measures) and another 54 regressions for the questionnaires (six ERP components by three electrode locations by three questionnaires).

Prediction for the dot-probe bias measures: The results for the prediction of the dot-probe bias measures are shown in Table 3. Results are reported as being significant at $\alpha \leq 0.05$. The following three predictions for dot-probe bias measures produced significant results, considering both novelty categories (learned and new pain-related words)

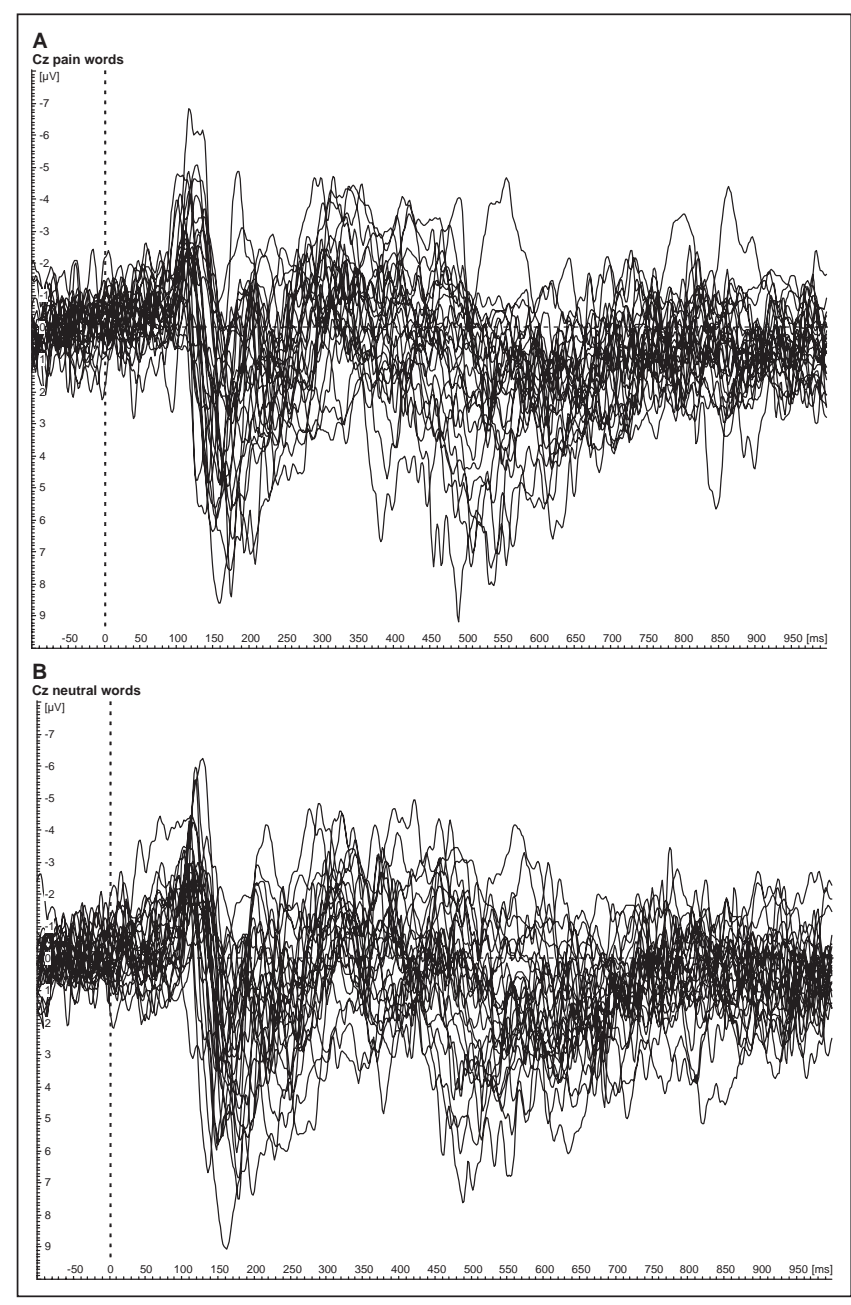

Figure 1) Graphs of individual event-related brain potential averages for 27 subjects for pain-related words (A) and neutral words (B). Variation of activation and prominent peaks are displayed. Differences in the eventrelated brain potentials of critical (pain-related words) and baseline (neutral words) stimuli cannot be shown with this mode of presentation because individual differences are comparatively high

combined as predictors: bias for pain-related words predicted by ERPs of LPC-Peaks at $\mathrm{Pz}\left(\mathrm{R}^{2}=0.297 ; \mathrm{P}=0.015\right)$, bias for social threat words predicted by ERPs of $\mathrm{P} 300$ at $\mathrm{Cz}\left(\mathrm{R}^{2}=0.153 ; \mathrm{P}=0.036\right)$, and bias for positive words predicted by ERPs of $\mathrm{N} 200$ at $F z\left(R^{2}=0.222 ; P=0.049\right)$.

The following six predictions for dot-probe bias measures produced significant results, considering only new pain words as predictors: bias for pain-related words predicted by ERPs of N100 at $\mathrm{Cz}\left(\mathrm{R}^{2}=0.184\right.$; $\mathrm{P}=0.026$ ), bias for pain-related words predicted by ERPs of LPC-Peaks at $\mathrm{Pz}\left(\mathrm{R}^{2}=0.220 ; \mathrm{P}=0.014\right)$, bias for social threat words predicted by ERPs of $\mathrm{P} 300$ at $\mathrm{F}_{z}\left(\mathrm{R}^{2}=0.232 ; \mathrm{P}=0.011\right)$, bias for positive words predicted by ERPs of LPC-Peaks at $F_{z}\left(R^{2}=0.148 ; P=0.047\right)$, bias for positive words predicted by ERPs of N200 at $F_{z}\left(R^{2}=0.168 ; P=0.034\right)$ and bias for positive words predicted by ERPs of LPC-Area at $\mathrm{Pz}\left(\mathrm{R}^{2}=0.149\right.$; $\mathrm{P}=0.047)$.

Interestingly, learned pain words did not allow for any significant predictions regarding the dot-probe bias measures. Furthermore, after Bonferroni correction, none of the predictions reached the level of significance. The relationship between the two types of implicit measures - namely dot-probe and ERP - was weak on average and reached significance only when new pain-related words were used in the ERP paradigm for prediction.

Prediction of self-report measures: The results of the predictions for the PCS, PASS and PVAQ are shown in Table 4. Results are reported 
TABLE 2

Results of ANOVAs with main effects for the WORDTYPE (pain-related words versus neutral words) and NOVELTY (learned words versus new words) factors, and effect sizes (partial eta)

\begin{tabular}{|c|c|c|c|c|c|c|c|}
\hline \multirow[b]{2}{*}{ Electrodes } & \multirow[b]{2}{*}{ Factors } & \multicolumn{2}{|c|}{ Fz } & \multicolumn{2}{|c|}{$\mathrm{Cz}$} & \multicolumn{2}{|c|}{$\mathrm{Pz}$} \\
\hline & & eta & $\mathbf{P}$ & eta & $\mathbf{P}$ & eta & $\mathbf{P}$ \\
\hline \multirow[t]{2}{*}{ N100 } & WORDTYPE & 0.037 & 0.326 & 0.036 & 0.330 & 0.119 & 0.091 \\
\hline & NOVELTY & 0.010 & 0.618 & $<0.001$ & 0.986 & 0.003 & 0.777 \\
\hline \multirow[t]{2}{*}{ P100 } & WORDTYPE & 0.287 & 0.003 & 0.194 & 0.020 & 0.092 & 0.117 \\
\hline & NOVELTY & 0.485 & $<0.001$ & 0.382 & 0.001 & 0.193 & 0.019 \\
\hline \multirow[t]{2}{*}{ N200 } & WORDTYPE & 0.258 & 0.006 & 0.184 & 0.023 & 0.303 & 0.002 \\
\hline & NOVELTY & 0.115 & 0.077 & 0.039 & 0.317 & 0.191 & 0.020 \\
\hline \multirow[t]{2}{*}{ P300 } & WORDTYPE & 0.052 & 0.241 & 0.202 & 0.016 & 0.427 & $<0.001$ \\
\hline & NOVELTY & 0.017 & 0.515 & 0.084 & 0.135 & 0.178 & 0.025 \\
\hline \multirow[t]{2}{*}{ LPC-Peaks } & WORDTYPE & 0.644 & $<0.001$ & 0.596 & $<0.001$ & 0.778 & $<0.001$ \\
\hline & NOVELTY & 0.415 & $<0.001$ & 0.395 & $<0.001$ & 0.432 & $<0.001$ \\
\hline \multirow[t]{2}{*}{ LPC-Area } & WORDTYPE & $<0.001$ & 0.931 & 0.053 & 0.239 & 0.106 & 0.090 \\
\hline & NOVELTY & 0.003 & 0.769 & 0.009 & 0.635 & 0.034 & 0.344 \\
\hline
\end{tabular}

Significant effects after correction for type 1 error (Bonferroni) are printed in bold. Late positive complex (LPC)-Area is the area under the curve in the time range from $400 \mathrm{~ms}$ to $800 \mathrm{~ms}$; LPC-Peaks is the most positive peak in the time range between $400 \mathrm{~ms}$ and $800 \mathrm{~ms}$ from trial onset

TABLE 3

Results of multiple regressions for dot-probe bias measures (pain words, social threat words and positive words) on six different event-related brain potential components (N100, P100, N200, P300, late positive complex [LPC]-Peaks and LPC-Area) assessed at Fz, Pz and Cz elicited by learned and new pain-related words, and by both word categories combined

\begin{tabular}{|c|c|c|c|c|c|c|c|c|c|c|c|c|c|c|}
\hline \multirow[b]{2}{*}{ Criteria } & \multirow[b]{2}{*}{ Electrode site } & \multirow[b]{2}{*}{ Predictor } & \multicolumn{2}{|c|}{ N100 } & \multicolumn{2}{|c|}{ P100 } & \multicolumn{2}{|c|}{ N200 } & \multicolumn{2}{|c|}{ P300 } & \multicolumn{2}{|c|}{ LPC-Peaks } & \multicolumn{2}{|c|}{ LPC-Area } \\
\hline & & & $\mathrm{R}^{2}$ & $P$ & $\mathbf{R}^{2}$ & $\mathbf{P}$ & $\mathbf{R}^{2}$ & $\mathbf{P}$ & $R^{2}$ & $\mathbf{P}$ & $\mathbf{R}^{2}$ & $\mathbf{P}$ & $R^{2}$ & $P$ \\
\hline \multirow[t]{7}{*}{ Pain } & $\mathrm{Fz}$ & Combined & 0.146 & 0.151 & 0.122 & 0.209 & 0.074 & 0.397 & 0.005 & 0.943 & 0.038 & 0.630 & 0.022 & 0.770 \\
\hline & & Learned & 0.005 & 0.733 & 0.101 & 0.107 & 0.036 & 0.342 & 0.004 & 0.761 & 0.036 & 0.332 & 0.001 & 0.858 \\
\hline & $\mathrm{Cz}$ & Combined & 0.192 & 0.078 & 0.037 & 0.636 & 0.007 & 0.924 & 0.002 & 0.973 & 0.070 & 0.420 & 0.026 & 0.725 \\
\hline & & Learned & 0.005 & 0.721 & 0.012 & 0.588 & 0.006 & 0.696 & 0.000 & 0.932 & 0.010 & 0.614 & 0.026 & 0.418 \\
\hline & & New & 0.184 & 0.026 & 0.033 & 0.366 & 0.000 & 0.987 & 0.002 & 0.848 & 0.060 & 0.219 & 0.002 & 0.847 \\
\hline & & Learned & 0.001 & 0.889 & 0.003 & 0.780 & 0.002 & 0.832 & 0.066 & 0.196 & 0.015 & 0.549 & 0.015 & 0.546 \\
\hline & & New & 0.059 & 0.222 & 0.131 & 0.064 & 0.020 & 0.483 & 0.011 & 0.597 & 0.220 & 0.014 & 0.061 & 0.214 \\
\hline \multirow[t]{6}{*}{ Social threat } & $\mathrm{Fz}$ & Combined & 0.088 & 0.330 & 0.186 & 0.084 & 0.014 & 0.849 & 0.240 & 0.037 & 0.056 & 0.502 & 0.064 & 0.453 \\
\hline & & Learned & 0.000 & 0.933 & 0.115 & 0.083 & 0.010 & 0.619 & 0.089 & 0.131 & 0.025 & 0.403 & 0.007 & 0.688 \\
\hline & & New & 0.082 & 0.136 & 0.092 & 0.124 & 0.001 & 0.894 & 0.232 & 0.011 & 0.027 & 0.411 & 0.061 & 0.214 \\
\hline & $\mathrm{Cz}$ & Combined & 0.053 & 0.521 & 0.127 & 0.196 & 0.053 & 0.520 & 0.153 & 0.036 & 0.012 & 0.807 & 0.036 & 0.642 \\
\hline & & Learned & 0.000 & 0.929 & 0.015 & 0.544 & 0.080 & 0.154 & 0.000 & 0.984 & 0.011 & 0.597 & 0.013 & 0.577 \\
\hline & & New & 0.033 & 0.363 & 0.001 & 0.885 & 0.001 & 0.871 & 0.012 & 0.581 & 0.001 & 0.851 & 0.001 & 0.902 \\
\hline \multirow[t]{9}{*}{ Positive } & $\mathrm{Fz}$ & Combined & 0.031 & 0.683 & 0.091 & 0.317 & 0.222 & 0.049 & 0.140 & 0.165 & 0.186 & 0.085 & 0.110 & 0.249 \\
\hline & & Learned & 0.005 & 0.730 & 0.033 & 0.366 & 0.010 & 0.616 & 0.086 & 0.137 & 0.028 & 0.404 & 0.014 & 0.553 \\
\hline & & New & 0.025 & 0.434 & 0.068 & 0.189 & 0.168 & 0.034 & 0.005 & 0.731 & 0.148 & 0.047 & 0.086 & 0.138 \\
\hline & $\mathrm{Cz}$ & Combined & 0.044 & 0.580 & 0.035 & 0.652 & 0.079 & 0.375 & 0.013 & 0.857 & 0.044 & 0.584 & 0.034 & 0.659 \\
\hline & & Learned & 0.043 & 0.300 & 0.020 & 0.478 & 0.036 & 0.345 & 0.007 & 0.671 & 0.003 & 0.788 & 0.008 & 0.649 \\
\hline & & New & 0.001 & 0.851 & 0.024 & 0.445 & 0.022 & 0.459 & 0.008 & 0.648 & 0.041 & 0.311 & 0.018 & 0.500 \\
\hline & $\mathrm{Pz}$ & Combined & 0.021 & 0.775 & 0.171 & 0.105 & 0.043 & 0.592 & 0.082 & 0.356 & 0.009 & 0.899 & 0.151 & 0.141 \\
\hline & & Learned & 0.020 & 0.485 & 0.135 & 0.060 & 0.001 & 0.890 & 0.074 & 0.171 & 0.008 & 0.666 & 0.018 & 0.502 \\
\hline & & New & 0.004 & 0.759 & 0.114 & 0.085 & 0.043 & 0.301 & 0.031 & 0.382 & 0.000 & 0.969 & 0.149 & 0.047 \\
\hline
\end{tabular}

Significant results $(P \leq 0.05)$ are printed in bold. LPC-Area is the area under the curve in the time range from $400 \mathrm{~ms}$ to $800 \mathrm{~ms}$; $L P C$-Peaks is the most positive peak in the time range between $400 \mathrm{~ms}$ and $800 \mathrm{~ms}$ from trial onset

as being significant at $\alpha \leq 0.05$. The PASS scores were significantly predicted by several ERPs (P100 at Fz: $\mathrm{R}^{2}=0.249, \mathrm{P}=0.032$; LPC-Area at $\mathrm{C} z: \mathrm{R}^{2}=0.250, \mathrm{P}=0.032$; LPC-Peaks at $\left.\mathrm{Cz}: \mathrm{R}^{2}=0.361, \mathrm{P}=0.005\right)$. $\mathrm{P} 300$ at $\mathrm{Pz}$ elicited by learned and new pain words combined significantly predicted the PVAQ scores $\left(\mathrm{R}^{2}=0.221 ; \mathrm{P}=0.050\right)$. After Bonferroni correction, none of the predictions were found to be significant.
Three predictions of self-report measures by ERP components elicited by new pain-related words only were significant: PASS by LPC-Peaks at $\mathrm{Cz} \quad\left(\mathrm{R}^{2}=0.361 ; \mathrm{P}=0.001\right)$, PVAQ by $\mathrm{P} 300$ at $\mathrm{Pz}$ $\left(\mathrm{R}^{2}=0.219 ; \mathrm{P}=0.014\right)$ and PASS by LPC-Area at $\mathrm{Cz} \quad\left(\mathrm{R}^{2}=0.237\right.$; $\mathrm{P}=0.010$ )

Three predictions of self-report measures by ERP components elicited by learned pain-related words only were significant: PCS by 
TABLE 4

Results of multiple regressions for the PCS, PASS and PVAQ questionnaires on six different event-related brain potential components (N100, P100, N200, P300, late positive complex [LPC]-Peaks and LPC-Area) assessed at Fz, Pz and Cz, elicited by learned and new pain-related words, and by both word categories combined

\begin{tabular}{|c|c|c|c|c|c|c|c|c|c|c|c|c|c|c|}
\hline \multirow[b]{2}{*}{ Criteria } & \multirow[b]{2}{*}{ Electrode site } & \multirow[b]{2}{*}{ Predictor } & \multicolumn{2}{|c|}{ N100 } & \multicolumn{2}{|c|}{ P100 } & \multicolumn{2}{|c|}{ N200 } & \multicolumn{2}{|c|}{ P300 } & \multicolumn{2}{|c|}{ LPC-Peaks } & \multicolumn{2}{|c|}{ LPC-Area } \\
\hline & & & $\mathrm{R}^{2}$ & $\mathbf{P}$ & $\mathrm{R}^{2}$ & $\mathbf{P}$ & $\mathrm{R}^{2}$ & $\mathbf{P}$ & $\mathrm{R}^{2}$ & $\mathbf{P}$ & $\mathrm{R}^{2}$ & $\mathbf{P}$ & $\mathrm{R}^{2}$ & $\mathbf{P}$ \\
\hline \multirow{6}{*}{ PCS } & & Learned & 0.013 & 0.578 & 0.188 & 0.024 & 0.096 & 0.116 & 0.004 & 0.759 & 0.008 & 0.660 & 0.003 & 0.794 \\
\hline & $\mathrm{Cz}$ & Combined & 0.007 & 0.918 & 0.030 & 0.691 & 0.117 & 0.224 & 0.048 & 0.556 & 0.139 & 0.166 & 0.045 & 0.575 \\
\hline & & Learned & 0.005 & 0.724 & 0.023 & 0.455 & 0.055 & 0.241 & 0.003 & 0.791 & 0.005 & 0.722 & 0.007 & 0.683 \\
\hline & & New & 0.005 & 0.738 & 0.002 & 0.814 & 0.092 & 0.123 & 0.037 & 0.336 & 0.134 & 0.061 & 0.044 & 0.295 \\
\hline & & Learned & 0.005 & 0.729 & 0.034 & 0.360 & 0.108 & 0.095 & 0.088 & 0.132 & 0.002 & 0.809 & 0.026 & 0.419 \\
\hline & & New & 0.002 & 0.844 & 0.016 & 0.528 & 0.001 & 0.881 & 0.099 & 0.110 & 0.039 & 0.321 & 0.010 & 0.614 \\
\hline \multirow[t]{5}{*}{ PASS } & $\mathrm{Fz}$ & Combined & 0.098 & 0.298 & 0.249 & 0.032 & 0.174 & 0.101 & 0.002 & 0.971 & 0.185 & 0.086 & 0.035 & 0.649 \\
\hline & & Learned & 0.082 & 0.148 & 0.230 & 0.011 & 0.146 & 0.050 & 0.002 & 0.825 & 0.059 & 0.224 & 0.000 & 0.700 \\
\hline & & New & 0.022 & 0.458 & 0.007 & 0.686 & 0.074 & 0.169 & 0.002 & 0.847 & 0.137 & 0.057 & 0.032 & 0.372 \\
\hline & $\mathrm{Cz}$ & Combined & 0.026 & 0.728 & 0.082 & 0.359 & 0.048 & 0.553 & 0.062 & 0.464 & 0.361 & 0.005 & 0.250 & 0.032 \\
\hline & & New & 0.002 & 0.846 & 0.053 & 0.250 & 0.001 & 0.906 & 0.148 & 0.047 & 0.088 & 0.132 & 0.104 & 0.101 \\
\hline \multirow[t]{9}{*}{ PVAQ } & $\mathrm{Fz}$ & Combined & 0.008 & 0.911 & 0.057 & 0.495 & 0.056 & 0.504 & 0.044 & 0.583 & 0.156 & 0.130 & 0.007 & 0.923 \\
\hline & & Learned & 0.008 & 0.666 & 0.047 & 0.278 & 0.022 & 0.455 & 0.038 & 0.330 & 0.030 & 0.387 & 0.006 & 0.704 \\
\hline & & New & 0.000 & 0.982 & 0.006 & 0.711 & 0.047 & 0.275 & 0.000 & 0.916 & 0.134 & 0.060 & 0.001 & 0.858 \\
\hline & $\mathrm{Cz}$ & Combined & 0.028 & 0.710 & 0.000 & 10.000 & 0.004 & 0.953 & 0.084 & 0.348 & 0.033 & 0.667 & 0.005 & 0.940 \\
\hline & & Learned & 0.004 & 0.763 & 0.000 & 0.998 & 0.003 & 0.779 & 0.004 & 0.759 & 0.005 & 0.732 & 0.000 & 0.926 \\
\hline & & New & 0.028 & 0.403 & 0.000 & 0.979 & 0.002 & 0.832 & 0.084 & 0.142 & 0.029 & 0.400 & 0.005 & 0.723 \\
\hline & $\mathrm{Pz}$ & Combined & 0.007 & 0.915 & 0.021 & 0.774 & 0.009 & 0.893 & 0.221 & 0.050 & 0.072 & 0.407 & 0.017 & 0.812 \\
\hline & & Learned & 0.004 & 0.751 & 0.010 & 0.615 & 0.009 & 0.637 & 0.010 & 0.613 & 0.003 & 0.794 & 0.009 & 0.639 \\
\hline & & New & 0.005 & 0.737 & 0.002 & 0.818 & 0.000 & 0.933 & 0.219 & 0.014 & 0.055 & 0.239 & 0.004 & 0.751 \\
\hline
\end{tabular}

Significant results $(P \leq 0.05)$ are printed in bold. LPC-Area is the area under the curve in the time range from $400 \mathrm{~ms}$ to $800 \mathrm{~ms}$; $L P C$-Peaks is the most positive peak in the time range between $400 \mathrm{~ms}$ and $800 \mathrm{~ms}$ from trial onset. PASS Pain Anxiety Symptoms Scale; PCS Pain Catastrophizing Scale; PVAQ Pain Vigilance and Awareness Questionnaire

$\mathrm{P} 100$ at $\mathrm{Fz}\left(\mathrm{R}^{2}=0.188 ; \mathrm{P}=0.024\right)$, PASS by $\mathrm{P} 100$ at $\mathrm{Fz}\left(\mathrm{R}^{2}=0.230\right.$; $\mathrm{P}=0.011)$ and PASS by $\mathrm{N} 200$ at $\mathrm{Fz}\left(\mathrm{R}^{2}=0.146 ; \mathrm{P}=0.050\right)$.

After Bonferroni correction for multiple testing, only the prediction of the PASS scores by LPC-Peaks at $\mathrm{Cz}$ remained significant $\left(\mathrm{R}^{2}=0.361 ; \mathrm{P}=0.001\right)$.

Summary: In Table 5, all predictions of the dot-probe bias measures and the pain-related questionnaire data (PCS, PASS and PVAQ) by ERPs elicited by pain-related words are summarized with regard to the frequency of significance. Altogether, 10 significant predictions of the questionnaire data are listed, of which the majority involve predictions of the PASS. For the dot-probe bias measures, nine significant predictions are listed, which equally involve all three bias indexes (pain-related words, social threat words and positive words). After Bonferroni correction, only the PASS could be significantly predicted once, with $\mathrm{R}^{2}=0.361$.

\section{DISCUSSION}

The present study intended to compare different variables of painrelated information processing such as pain anxiety, pain catastrophizing, hypervigilance to pain and attentional bias when pain- and nonpain-related stimuli were processed. These variables were grouped into implicit measures, ie, measures tapping into preconscious stages of information processing (dot-probe task and ERPs) and explicit measures, ie, variables based on self-observation and self-report (questionnaires). We hypothesized that variables within the implicit domain correlate highly - namely, the bias for pain-related stimuli in the dotprobe task and ERPs elicited by pain words in the lexical decision task (convergent validity). Furthermore, we hypothesized that variables belonging to different domains (implicit versus explicit) produce lower correlations - namely, the bias for pain-related words in the dot-probe task and ERPs elicited by pain words on the one hand and self-report variables for pain hypervigilance, pain anxiety and pain catastrophizing on the other hand (discriminant validity).

However, we could not find substantial associations between the behavioural and electrophysiological measures (within-domain comparison of implicit measures). Using ERP data as predictors, only a few dot-probe bias measures could be predicted significantly and this was reduced to zero when the Bonferroni correction was applied (hypothesis 1: convergent validity). Because a further reduction of correlations was impossible, the assumption of lower correlations between variables across different domains (implicit versus explicit) could not be verified (hypothesis 2: discriminant validity). The cross-domain comparisons actually produced slightly higher correlations, whereas the prediction of the PASS scores by the LPC at $\mathrm{Cz}$ withstood even Bonferroni correction.

The idea of a single underlying mechanism for pain-related information processing that can be assessed convergently by different implicit measures needs discussion. In this context, there is a small trend of studies that compare the Stroop paradigm with the dot-probe task (13). Data collected from the dot-probe task and the Stroop task have been directly compared in a number of studies on information processing in anxiety (36-38), whereas such comparisons have rarely been performed in the field of pain. In a study (20) with dot-probe and Stroop task data based on pain-related cues in samples of chronic pain 
patients and healthy controls, correlational analysis revealed a consistent lack of association. Thus, it was concluded that the dot-probe and Stroop tasks assess different attentional phenomena. Comparisons of these implicit measures when targeting fear-related cues also produced mixed evidence in anxiety research. Mogg et al (36) found no correlations between dot-probe and Stroop indexes, whereas Brosschott et al (37) reported small positive correlations. Egloff and Hock (38) reported moderate correlations between these tasks. Altogether, no consensus has been established on whether the dot-probe and Stroop tasks assess similar or diverging cognitive processes, and the question of correlations among implicit measures has remained unanswered on the basis of these data.

This undetermined situation with regard to the convergence of different implicit measures of pain-related information processing was the reason we tested an alternative to the Stroop paradigm task. ERP recordings appear to be the method of choice because they allow for assessment of the neural activity associated with the cognitive processes under investigation. ERPs provide the opportunity to precisely retrace single stages in the information processing chain and, therefore, can be informative about very early stages, ie, preconscious processing. However, the associations of the parameters gained in the dot-probe task and lexical decision task designed to assess ERPs were against our expectations - low.

Some discussion about the architecture of the two tasks is required at this point. In both paradigms, the primary tasks did not require the subjects to attend to the emotional word meaning. For correct responses in the dot-probe task, processing the word meaning was not necessary at all. In the lexical decision test, superficial processing of the words was sufficient to determine lexically whether a word was meaningful or nonsense. Accordingly, explicit conscious word processing might have been promoted slightly more often in the lexical decision test than in the dot-probe task. Because the word presentation times and the requirement to respond quickly were similar between the two tasks, the small difference in engaging only implicit preconscious or also explicit conscious processing might have been critical. We used established test paradigms in the present study. However, newly designed paradigms considering this difference might be useful for the future.

Regarding our second hypothesis (ie, measures across domains [implicit versus explicit] have a weaker association than measures within one domain [implicit]), we found one significant correlation (LPC at $\mathrm{Cz}$ predicted the PASS scores significantly) for the acrossdomain comparison, whereas for the within-domain comparison of implicit measures, no significant associations were found. The correlation coefficients testing convergent validity were assumed to be higher than correlation coefficients testing discriminant validity. Given the low correlations in the within-domain comparison of implicit measures (convergent validity), appropriate testing for discriminant validity was impossible. However, the weak correlations between behavioural and physiological measures of processing pain-related information on the one hand and self-report data on pain hypervigilance, pain anxiety and pain catastrophizing on the other hand deserve comment in any case. A recent study from our laboratory (Physiological Psychology, University of Bamberg) (39) with a large sample of 94 subjects also could not provide evidence for a substantial relationship between behavioural and self-report measures for pain-related information processing. This finding of a lack of association between behavioural and self-report measures is by no means new (21-23), although some early reports seemed to corroborate the assumption of more biased attention to pain-related cues according to the dot-probe task in individuals with increased levels of pain-related fear or anxiety as indicated by self-report $(10,14)$. It might be assumed that stable relationships emerge under conditions of threat, but more research is needed for confirmation.

Despite the criticism of the comparability of the two implicit tasks in the present study, the application of ERPs has, in general, been shown to be fruitful to detect pain-related information processing. The
TABLE 5

Summary of the number of significant predictions of the questionnaire data and dot-probe bias measures by event-related brain potential components elicited by learned and new pain-related words, and by both word categories combined, presented for different levels of significance testing

\begin{tabular}{|c|c|c|c|c|}
\hline \multirow[b]{2}{*}{ Criteria } & \multirow[b]{2}{*}{ Predictor } & \multicolumn{3}{|c|}{ Level of significance testing } \\
\hline & & $P \leq 0.05$ & $P \leq 0.01$ & $P \leq 0.001$ \\
\hline \multirow[t]{3}{*}{$\overline{\text { PASS }}$} & Combined & 2 & $1\left(R^{2}=0.361\right)$ & 0 \\
\hline & New & 0 & 1 & $1\left(R^{2}=0.361\right)$ \\
\hline & Learned & 2 & 0 & 0 \\
\hline \multirow[t]{3}{*}{ PVAQ } & Combined & 1 & 0 & 0 \\
\hline & New & 1 & 0 & 0 \\
\hline & Learned & 0 & 0 & 0 \\
\hline \multirow[t]{3}{*}{ PCS } & Combined & 0 & 0 & 0 \\
\hline & New & 0 & 0 & 0 \\
\hline & Learned & 1 & 0 & 0 \\
\hline \multirow[t]{3}{*}{ Pain words } & Combined & 1 & 0 & 0 \\
\hline & New & 2 & 0 & 0 \\
\hline & Learned & 0 & 0 & 0 \\
\hline \multirow[t]{3}{*}{ Positive words } & Combined & 1 & 0 & 0 \\
\hline & New & 3 & 0 & 0 \\
\hline & Learned & 0 & 0 & 0 \\
\hline \multirow{3}{*}{$\begin{array}{l}\text { Social threat } \\
\text { words }\end{array}$} & Combined & 1 & 0 & 0 \\
\hline & New & 1 & 0 & 0 \\
\hline & Learned & 0 & 0 & 0 \\
\hline
\end{tabular}

For significant predictions at $P \leq 0.01$, the total explained variance is listed. PASS Pain Anxiety Symptoms Scale; PCS Pain Catastrophizing Scale; PVAQ Pain Vigilance and Awareness Questionnaire

ANOVAs of our ERP data showed significant differences between pain-related and neutral words. These differences also indicated the validity of the method with regard to the specificity of processing painrelated information when applied in a nonclinical sample. The effects of the different word categories on different ERP components are in line with findings reported in the literature regarding early negative components $(27,28)$, P300 (29) and LPC (40).

The current study has some limitations. Due to the small sample size, the statistical power was potentially low. Consequently, the number of predictors included in single regression analysis also had to be kept low. Therefore, the overall number of regression analyses was high and required rigorous correction for type 1 error, potentially allowing too liberally for type 2 errors. For these reasons, the results must be seen as preliminary. The within-domain comparisons between self-report measures of pain hypervigilance, pain anxiety and pain catastrophizing were deliberately not stressed in the present report because these measures tend to lose specificity in pain-free individuals under nonthreat conditions, as shown in earlier studies from our laboratory $(39,41)$.

\section{SUMMARY}

The correlations within the implicit measures of processing painrelated information (dot-probe task including pain words, and ERPs elicited by pain-related words) were observed to be low, challenging the assumption of a single attentional process underlying these measures. Furthermore, these measures also did not appear to be strongly related to the self-report of pain hypervigilance, pain anxiety and pain catastrophizing.

ACKNOWLEDGEMENTS: This study was supported by research grants from the Deutsche Forschungsgemeinschaft (LA 685/6 and LA 685/7) and by a research grant from the Robert Pfleger-Stiftung Bamberg "Interdisziplinäre Schmerzforschung" (Germany). 


\section{REFERENCES}

1. McCracken LM, Zayfert C, Gross RT. The Pain Anxiety Symptoms Scale: Development and validation of a scale to measure fear of pain. Pain 1992;50:67-73

2. Sullivan MJ, Bishop S, Pivik J. The Pain Catastrophizing Scale: Development and validation. Psychol Assess 1995;7:527-32.

3. McCracken LM. Attention to pain in persons with chronic pain: A behavioral approach. Behav Ther 1997;28:271-84.

4. Crombez G, Eccleston C, Baeyens F, Eelen P. When somatic information threatens, catastrophic thinking enhances attentional interference. Pain 1998;75:187-98.

5. Asmundson GJG. Understanding and Treating Fear and Pain. Oxford: Oxford University Press, 2007.

6. Crombez G, Van Damme S, Eccleston C. Hypervigilance to pain: An experimental and clinical analysis. Pain 2005;116:4-7.

7. Mathews A, Macleod CM. Selective processing of threat cues in anxiety states. Behav Res Ther 1985;23:563-9.

8. Macleod CM, Mathews A, Tata P. Attentional biases in emotional disorders. J Abnorm Psych 1986;53:1-15.

9. Pearce J, Morley S. An experimental investigation of the construct validity of the McGill Pain Questionnaire. Pain 1989;39:115-21.

10. Keogh E, Ellery D, Hunt C, Hannent I. Selective attentional bias for pain-related stimuli amongst pain fearful individuals. Pain 2001;91:91-100.

11. Williams JMG, Watts FN, MacLeod C, Mathews A. Cognitive Psychology and Emotional Disorders. Chichester: Wiley, 1988.

12. Crombez G, Hermans D, Adriaensen H. The emotional Stroop task and chronic pain: What is threatening for chronic pain sufferers? Eur J Pain 2000;4:37-44.

13. Roelofs J, Peters ML, Zeegers MP, Vlaeyen JW. The modified Stroop paradigm as a measure of selective attention towards pain-related stimuli among chronic pain patients: A meta-analysis. Eur J Pain 2002;6:273-81.

14. Keogh E, Dillon C, Georgius G, Hunt U. Selective attentional biases for physical threat in physical anxiety sensitivity. J Anxiety Disord 2001;15:299-315.

15. Khatibi A, Dehghani M, Sharpe L, Asmundson GJ, Pouretemad H. Selective attention towards painful faces among chronic pain patients: Evidence from a modified version of the dot-probe. Pain 2009; 142:42-7.

16. Moss-Morris R, Petrie KJ. Experimental evidence for interpretive but not attention biases towards somatic information in patients with chronic fatigue syndrome. Br J Health Psychol 2003;8:195-208.

17. Roelofs J, Peters ML, Fassart T, Vlaeyen JW. The role of movement and injury in selective attentional processing in patients with chronic low back pain: A dot-probe evaluation. J Pain 2005;6:294-300.

18. Pincus T, Fraser L, Pearce S. Do chronic pain patients Stroop on pain stimuli? Br J Clin Psychol 1998;37:49-58.

19. Andersson G, Haldrup D. Personalized pain words and Stroop interference in chronic pain patients. Eur J Pain 2003;7:431-8.

20. Asmundson G, Wright KD, Hadjistavropoulos HD. Hypervigilance and attentional fixedness in chronic musculoskeletal pain: Consistency of findings across modified Stroop and dot-probe tasks. J Pain 2009;6.8:497-506.

21. Keogh E, Cochrane M. Anxiety sensitivity, cognitive biases, and the experience of pain. J Pain 2002;3:320-9.

22. Keogh E, Thompson T, Hannent I. Selective attentional bias, conscious awareness and the fear of pain. Pain 2003;104:85-91.

23. Roelofs J, Peters ML, Van der Zijden M, Thielen FG, Vlaeyen JW. Selective attention and avoidance of pain-related stimuli:
A dot-probe evaluation in a pain-free population. J Pain 2003;6:322-8.

24. Montoya P, Pauli P, Batra A, Wiedemann G. Altered processing of pain-related information in patients with fibromyalgia. Eur J Pain 2005; 7.5:293-303.

25. Sitges C, García-Herrera M, Pericás M, Collado D, Truyols M, Montoya P. Abnormal brain processing of affective and sensory pain descriptors in chronic pain patients. J Aff Disord 2007;104-3:73-82.

26. Larbig W, Montoya P, Flor H. Evidence for a change in neural processing in phantom limb pain patients. Pain 1995;67:275-83.

27. Knost B, Flor H, Braun C, Birbaumer N. Cerebral processing of words and the development of chronic pain. Psychophysiology 1997;34:474-81.

28. Flor H, Knost B, Birbaumer N. Processing of pain- and body-related verbal material in chronic patients: Central and peripheral correlates. Pain 1997;73:413-21.

29. Nikendei C, Dengler W, Wiedemann G, Pauli P. Selective processing of pain-related word stimuli in subclinical depression as indicated by event-related brain potentials. Biol Psychol 2005; 70:52-60.

30. Lang PJ. Anxiety: Toward a psychophysiological definition. In: Akiskal HS, Webb WL, eds. Psychiatric Diagnosis: Exploration of Biological Criteria. New York: Spectrum, 1978.

31. Eysenck MW. Anxiety. Hove: Lawrence Erlbaum Associates Ltd, 1992.

32. Walter B, Hampe D, Wild J. Die Erfassung der Angst vor Schmerz: Eine modifizierte deutsche Version der Pain Anxiety Symptom Scale (PASS-D). Der Schmerz 2002;15:1.

33. Roelofs J, Peters ML, Vlaeyen JW. Selective attention for painrelated information in healthy individuals: The role of pain and fear. Eur J Pain 2002;6:331-9.

34. Roelofs, J, McCracken L, Peters ML. Psychometric evaluation of the Pain Anxiety Symptoms Scale (PASS) in chronic pain patients. J Behav Med 2004;27:167-83.

35. Gratton G, Coles MM, Donchin A. A new method of off-line removal of ocular artefact. Electroenceph Clin Neurophysiol 2008;55:468-84.

36. Mogg K, Bradley B, Dixon C, Fisher S, Twelftree H, McWilliams A. Trait anxiety. Defensiveness and selective processing of threat: An investigation using two measures of attentional bias. Pers Ind Diff 2000;28:1063-77.

37. Brosschott JF, de Ruiter C, Kindt M. Processing bias in anxious subjects and repressors, measured by emotional Stroop interference and attentional allocation. Pers Ind Diff 1999;26:777-93.

38. Egloff B, Hock M. Assessing attention allocation toward threat-related stimuli: A comparison of the emotional Stroop task and the attentional probe task. Pers Indiv Diff 2003;35:475-83.

39. Huber C, Kunz M, Artelt C, Lautenbacher S. Attentional and emotional mechanisms of pain processing and their related factors: A structural equations approach. Pain Res Manage 2010;15:229-37.

40. Naumann E, Bartussek D, Diedrich O, Laufer M. Assessing cognitive and affective information processing functions of the brain by means of the late positive complex of the event-related potential. J Psychophysiol 1992;6:285-98.

41. Baum R, Huber C, Schneider R, Lautenbacher S. Prediction of experimental pain sensitivity by the attention to pain-related stimuli in healthy individuals. Percept Mot Skills 2011. (In press) 


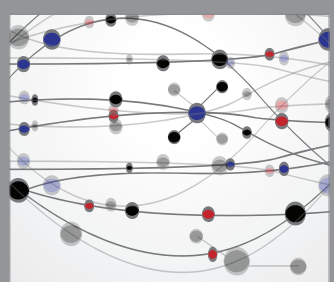

The Scientific World Journal
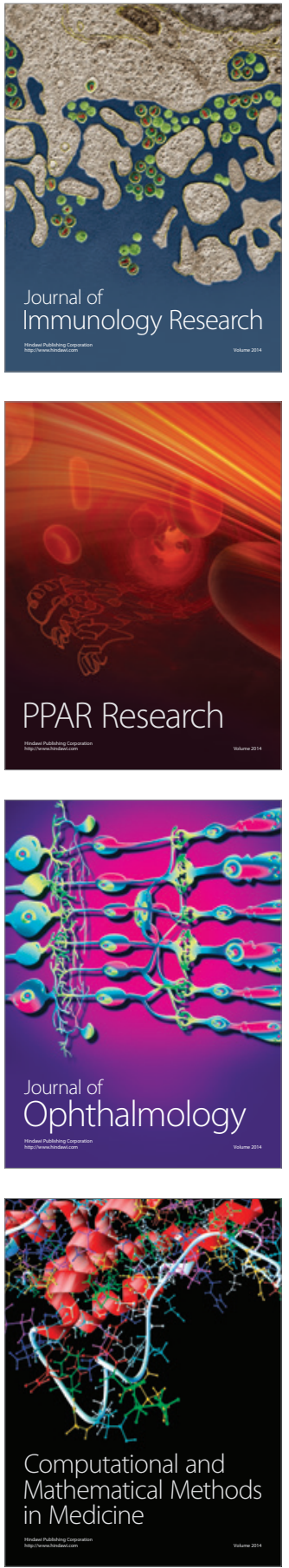

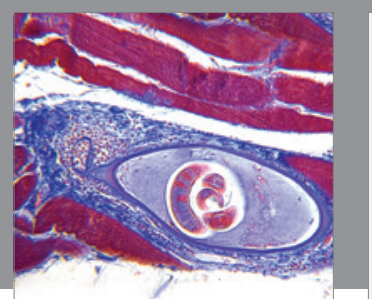

Gastroenterology Research and Practice

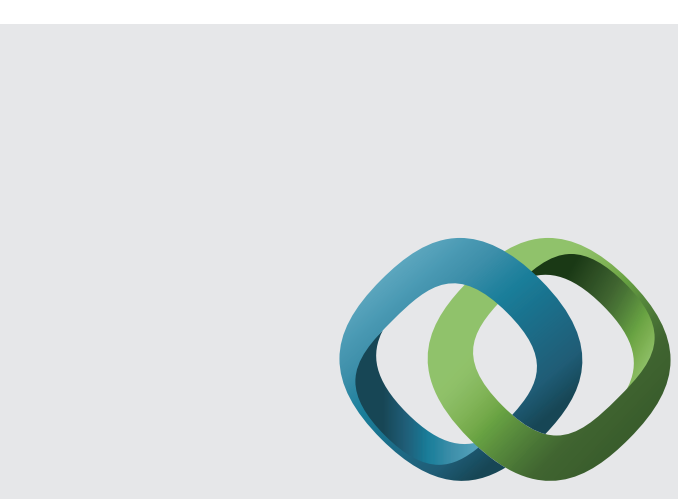

\section{Hindawi}

Submit your manuscripts at

http://www.hindawi.com
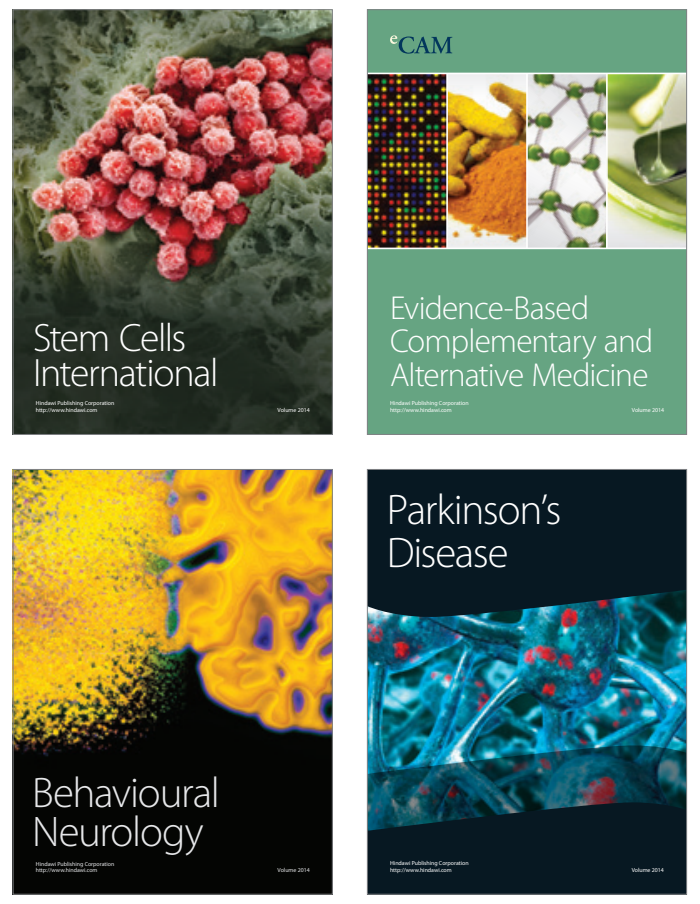
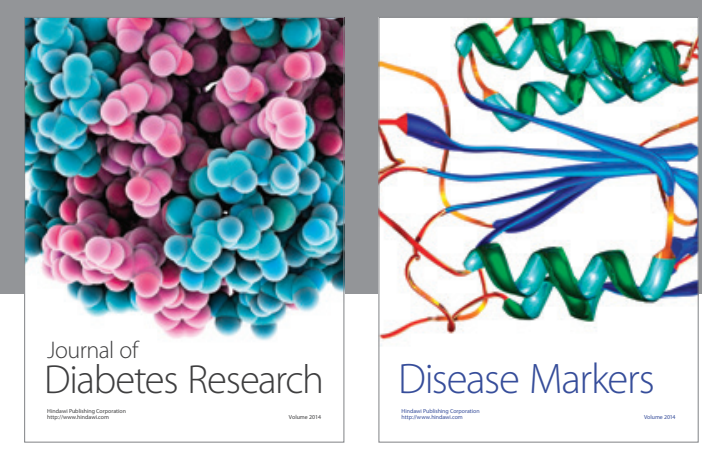

Disease Markers
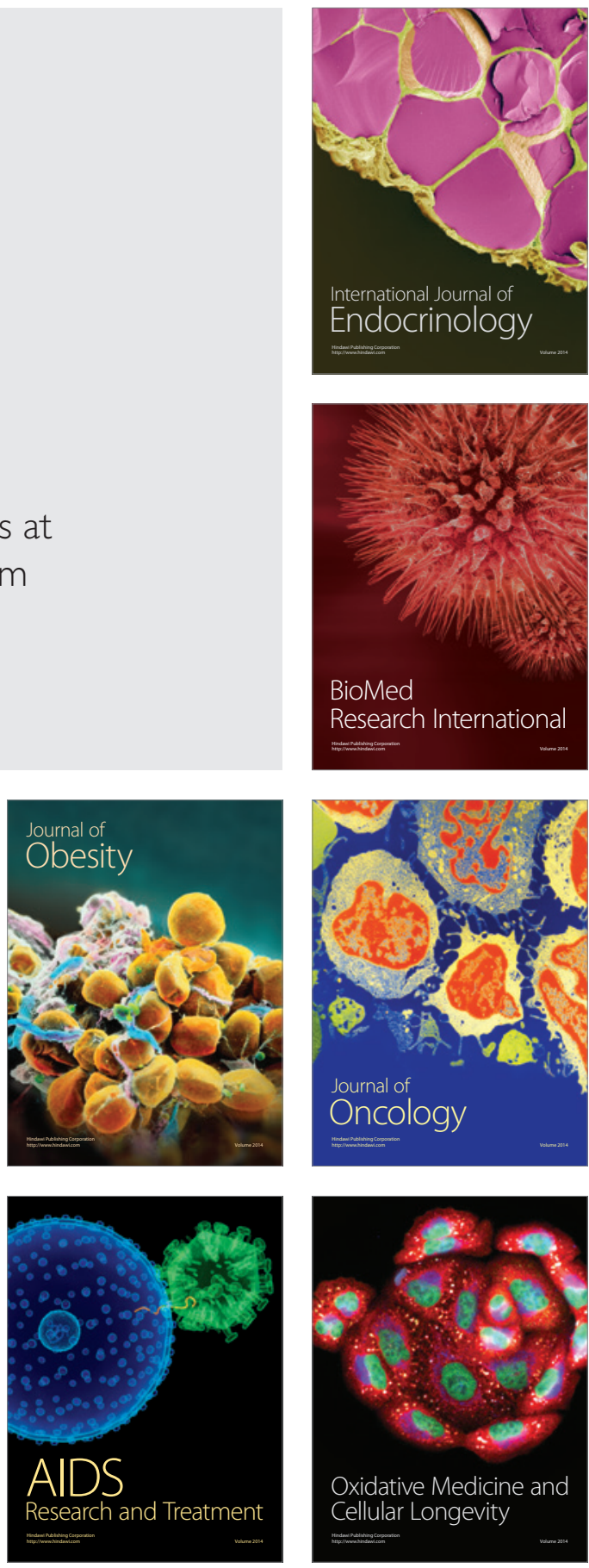